\title{
Measuring the Impact of Infectious Diseases on Tourists' Willingness to Pay to Visit Island Destinations
}

\author{
Carmelo J. León, Yen E. Lam-González *®D , Carmen García Galindo ${ }^{\circledR}$ and \\ Matías M. González Hernández \\ Institute of Tourism and Sustainable Economic Development (TIDES), Campus de Tafira, \\ University of Las Palmas de Gran Canaria, 35017 Las Palma, Spain; carmelo.leon@ulpgc.es (C.J.L.); \\ carmen.garciagalindo@ulpgc.es (C.G.G.); matiasmanuel.gonzalez@ulpgc.es (M.M.G.H.) \\ * Correspondence: yen.lam@ulpgc.es
}

Received: 1 September 2020; Accepted: 14 October 2020; Published: 18 October 2020

\begin{abstract}
The occurrence of infectious diseases may change tourists' perceptions of a destination's image and value. This article proposes and empirically tests a choice model to measure the effect of the risk of infectious disease outbreaks caused by climate change on tourists' willingness to pay for holidays to island destinations. With this aim, an online survey was administrated to 2538 European frequent travellers at their country of residence. Tourists were presented with a hypothetical situation whereby they had to choose among eleven well-known European island destinations for their next holiday. The choice cards included the probability of the occurrence of infectious disease events in the context of other potential risks caused by climate change (i.e., forest fires, floods, heat waves, etc.). The results show infectious disease is the risk that more negatively affects tourists' willingness to pay to visit islands, followed by forest fires. The results have implications for tourism policy, highlighting the importance of prevention and response strategies, and the design of climate-oriented services, which may raise opportunities to work towards the enhancement of those health and environmental conditions of tourist destinations that ensure their sustainability in the longer term.
\end{abstract}

Keywords: tourism; climate change; islands; infectious diseases; adaptation; resilience; blue growth

\section{Introduction}

The tourism industry is subject to the impacts of climate change (CC), and this is likely to produce significant economic effects [1,2]. The identification and the study of these impacts help detect the appropriate adaptation and mitigation policy measures that could be implemented at tourist destinations, thus contributing to the sustainability of their tourism-based economies [3].

Although climate change is expected to have pronounced indirect effects via disease spreading [4], very few studies focus on tourism welfare or demand being affected by vector-borne infectious disease outbreaks [5]. In response, the present paper aims to analyse the effect of the risk of infectious disease events caused by climate change on tourists' willingness to pay to visit island destinations. Given the multiple ways in which climate change can impact tourist destinations, the paper also includes other impacts, thus leading to a more complex picture of tourists' preferences and behavioural response to climate change.

To do so, a set of discrete choice experiments (DCEs) has been employed with a total of 2538 European citizens (frequent travellers) surveyed at their country of origin. Subjects were presented with hypothetical scenarios, in which some EU island destinations were suffering several climate change impacts, including infectious disease events. They were asked to select only one 
alternative- -that is, visiting one of the islands at a given price, or staying at home with no cost. The analysis of all responses allows us to understand which climate risks have a greater impact on tourists' decisions to visit a specific island, and the price they are willing to pay to visit that destination.

Although many important attributes, such as climate, as well as the consequences of a changing climate, are outside the control of tourism practitioners and policy makers, they can nevertheless utilise this knowledge to improve the predictability of climate change impacts on island destinations and develop their marketing plans and tourism services accordingly.

The paper is structured as follows: The theoretical background section presents a general overview of previous research assessing the impact of climate change on infectious disease events, and the subsequent economic impacts on tourist destinations. The third section describes the model, the attributes utilised and their measurement. It also presents the fieldwork, the research instruments utilised for data collection, and the sample construction. Section 4 discusses the results of the model and, finally, Section 5 is dedicated to the discussion and conclusions of the research and offers additional remarks.

\section{Theoretical Background}

The long-term sustainability of tourism depends on the preservation and enhancement of the environment [6]. Climate change affects several services that ecosystems provide to tourism $[3,7,8]$. For example, more frequent and severe heatwaves or beach loss due to sea level rise and coastal erosion influence the value of the recreational experience at destinations, hence affecting tourism demand (arrivals and receipts) [5].

Climate change is also expected to have pronounced indirect effects via disease spreading [2]. In light of globalisation and increased population mobility, the geographical spread of certain diseases is changing rapidly, urging it to be seriously considered in the process of diagnosing them. Tourists are a particularly vulnerable population subgroup, especially when they choose a destination with environmental features that are drastically different from those of their country of origin. The health and medical literature, however, generally does not focus on tourists, and more often considers increased risk for various demographic groups of the indigenous population [3].

A review of the literature shows that there is abundant evidence on the effects of CC on tourism flows, expenditure and destination choice [7,9-11]. However, very few studies manage to pin down the market and non-market effects of the risk of infectious diseases, which mirrors the little relevance that academics have given to this research field.

Among the few available studies, $[4,12]$ examined the potential effects of CC on the spread of leptospirosis, concluding that higher temperatures, extreme weather events and flooding will result in the increased incidence and magnitude of this disease. The results reveal that travellers are at risk even if they are in good health, because the disease is often under-diagnosed in their home countries. Moreover, the literature highlights that adventure-seeking tourists are the most susceptible to leptospirosis. Therefore, it should be noted that different types of tourism exhibit different levels of exposure to health risks. For example, cruise tourism is one of the most vulnerable segments according to the study of [5].

From an economic perspective, disease spreading can have significant economic impacts on tourism destinations. Developing countries are likely to be the most vulnerable since they are often highly dependent on the tourism industry and also have inferior health care services and hygienic conditions. The study of [13] estimates potential losses for the tourism industry in a hypothetical scenario of an outbreak of chikungunya and dengue in Gujarat (an economically important state in India), Malaysia, and Thailand. Under the assumption of a $4 \%$ annual decline in the number of international tourists from non-endemic countries, the losses of tourism revenues are estimated to be about USD 8 million for Gujarat, USD 65 million for Malaysia, and USD 363 million for Thailand. To demonstrate the relative importance of these values, the authors provide comparison with the real annual cost of chikungunya and dengue for these economies: USD 90 million, USD 133 million, 
and approximately USD 127 million, respectively, thus revealing that highly tourism-dependent Thailand would incur extremely high losses.

The 2020 outbreak of COVID-19 shows that the impact of a serious disease outbreak at tourist destinations is highly disruptive, with the whole sector quickly coming to a complete standstill. Such serious diseases are also likely to modify tourists' behaviour in the medium-long term [14]. Although the current health crisis is not directly linked to CC, it will reshape tourism research in the near future, infectious diseases, both their causes and prevention, being a great challenge. Changes in tourism as a result of COVID-19 will be uneven in space and time [15]. On the other hand, global travel restrictions have led to a rapid recovery of certain ecosystems, which can have a drastic impact on the behavioural response of more environmentally responsible tourists. Such a response requires a tourism framework that redefines and reorients research after the COVID-19 pandemic. Thus, this paper centres on the effects that the potential spreading of an infectious disease, as a consequence of climate change, can have on tourists' choice of island destinations to travel to and their decisions on expenditure.

\section{Methodology}

There is a growing body of literature employing Discrete Choice Experiments (DCEs) to assess the environmental decision making of tourists which concludes that consumers care about the environment and tend toward more environmentally sustainable options and activities [16-18]. However, its application is scarce in the context of tourists' preferences and decisions to visit island destinations thought to be at risk due to the effects of climate change.

The starting point was the belief that the risk of health insecurity caused by infectious disease events will affect the value tourists assign to an island destination, leading to a decrease in their willingness to pay to visit this island. The next subsections are dedicated to describing the choice model, as well as the experimental conclusions that can be drawn, the variables utilised and their measurement, the research instrument and the characteristics of the sample.

\subsection{The Model}

The Discrete Choice Experiments (DCEs) technique has been widely applied to the evaluation of tourists' preferences both in natural areas and other tourism contexts [19]. The growing body of literature on this field serves to emphasise the increasing role that DCEs are playing in environmental decision making in recent years [18]. It involves asking tourists to choose between alternative profiles or sets of attributes of the destinations, each containing a set of mutually exclusive hypothetical alternatives [18]. It allows the effect of several attributes to be investigated simultaneously. It also avoids the often found "scale perception bias" when using Likert scales to elicit individual preferences [20-22].

Individuals' choices imply implicit trade-offs between the levels of the attributes in the different alternatives included in a choice set. In particular, tourists will pick the one providing the highest utility, which depends on the attribute levels of each alternative and on the tourists' preferences. The resulting choices are finally analysed to estimate the contribution of each attribute and level to the overall utility of individuals. Moreover, when the price is included as another attribute, marginal utility can easily be converted into willingness-to-pay (WTP) estimates for changes in the attribute levels [20].

The DCE method is derived from Lancaster's characteristics of value theory, which states that any good may be described by a bundle of characteristics and the levels that these may take [23]. A baseline or opt-out alternative must be included to avoid the problem of respondents being forced to choose options when they may not prefer any [24].

Choice experiments share a common theoretical framework with dichotomous-choice contingent valuation in the Random Utility Model [25], as well as a common basis of empirical analysis in limited dependent variable econometrics [26]. According to this framework, the indirect utility function for each respondent $i(U)$ can be decomposed into two parts: a deterministic element $(V)$, which is typically specified as a linear index of the attributes $(X)$ of the $\varphi$ different alternatives in the choice set, and a 
stochastic element (e), which represents unobservable influences on individual choice. This is shown in Equation (1):

$$
U_{i j}=V_{i j}\left(X_{i j}\right)+e_{i j}=b X_{i j}+e_{i j}
$$

Thus, the probability that any particular respondent will prefer option $g$ in the choice set to any alternative option $h$, can be expressed as the probability that the utility associated with option $g$ exceeds that associated with all other options, as stated in Equation (2):

$$
P\left[\left(U_{i g}>U_{i h}\right) \forall h \neq g\right]=P\left[\left(V_{i g}-V_{i h}\right)>\left(e_{i h}-e_{i g}\right)\right]
$$

In order to derive an explicit expression for this probability, it is necessary to know the distribution of the error term $\left(e_{i j}\right)$ :

$$
P\left(e_{i j} \leq t\right)=F(t)=\exp (-\exp (-t))
$$

The above distribution of the error term implies that the probability of any preferred alternative $g$ can be expressed in terms of the logistic distribution [25], as stated in Equation (4). This specification is known as the conditional logit model:

$$
P\left(U_{i g}>U_{i h}, \forall h \neq g\right)=\frac{\exp \left(\mu V_{i g}\right.}{\sum_{j} \exp \left(\mu V_{i j}\right)}
$$

where $\mu$ is a scale parameter, inversely proportional to the standard deviation of the error distribution. This parameter cannot be separately identified and is therefore typically assumed to be one. Thus, the model can be estimated by conventional maximum likelihood procedures, with the respective log-likelihood functions stated. Socio-economic variables can be included along with the choice set attributes. Once the parameter estimates have been obtained, a monetary compensating surplus welfare measure that conforms to demand theory can be derived for each attribute using the formula given by (5) [27],

$$
\text { Monetary value }=\frac{\ln \left\{\frac{\sum_{i} \exp \left(V_{i}^{1}\right)}{\sum_{i} \exp \left(V_{i}^{0}\right)}\right\}}{b_{c}}
$$

where $V_{0}$ represents the utility of the initial state and $V_{1}$ represents the utility of the alternative state. The coefficient $b_{c}$ gives the marginal utility of income and is the coefficient of the cost attribute. It is relatively straightforward to show that for the linear utility index specified in (1), the above formulae can be simplified to the ratio of coefficients given in Equation (6), where $b_{x}$ is the coefficient of any of the (non-monetary) attributes and $b_{c}$ is the coefficient of the cost attribute. These ratios are often known as implicit prices.

$$
\text { Monetary value }=\left|\frac{b_{x}}{b_{c}}\right|
$$

Choice experiments are therefore consistent with utility maximisation and demand theory, at least when a status quo option is included in the choice set.

\subsection{Attributes Levels and Measurement}

In our model, the attribute is the potential climate risk-that is, the probability of becoming infected when visiting a tourist destination impacted by infectious disease events caused by CC. Three potential levels of the attribute are considered: no impact (current situation), moderate impact, and strong impact, as shown in Figure 1. Although the focus of the analysis is on infectious diseases, a further eight climate-related impacts were included in the model, using the same classification. This allows the impact of infectious diseases to be analysed in a comparative way. 

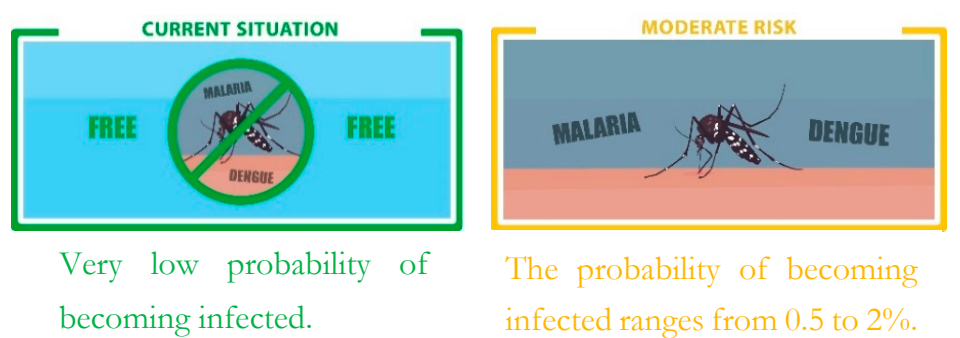

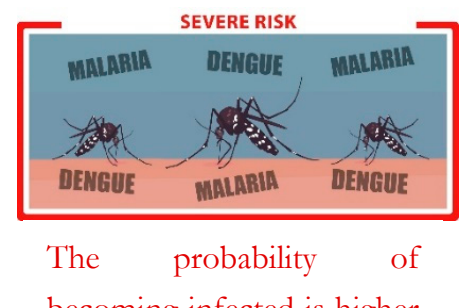

becoming infected is higher than $4 \%$.

Figure 1. Attribute levels for infectious diseases.

Eleven European islands and archipelagos are included as categorical variables in the model, joined to 5 levels of price for visiting the islands (see Table 1). Applying a Bayesian efficient design, a set of 24 combinations was obtained and translated into choice cards. With this information, tourists were asked to choose between two islands at a specified price, or "staying at home" (price $=0$ EUR) while each island presented a combination of potential risks caused by climate change. Table 1 shows the description of the attributes, levels and their measurement for this particular model.

Table 1. Description of attributes considered in the choice experiment.

\begin{tabular}{|c|c|c|c|}
\hline Attribute & Short Description & Levels & Model \\
\hline Island destination & Island destination brand & $\begin{array}{l}\text { Variable with } 11 \text { categories, one per } \\
\text { island (Canary Islands, Malta } \\
\text { Corsica, Cyprus, Madeira, Sardinia, } \\
\text { Sicily, Azores, Balearic Islands, Crete, } \\
\text { Martinique/Guadeloupe) }\end{array}$ & $\begin{array}{c}\text { Categorical variable } \\
\text { (dummy for each island) }\end{array}$ \\
\hline Price & $\begin{array}{l}\text { Price per day per person, for a 5-days } \\
\text { trip, including transportation cost and } \\
\text { cost of a four stars hotel accommodation }\end{array}$ & $\begin{array}{c}\text { Five categories: } \\
\text { EUR 0 if stay at home; } \\
\text { EUR 100; EUR 150; EUR 200; EUR } 300\end{array}$ & Continuous variable. \\
\hline Infectious diseases & $\begin{array}{l}\text { Probability of becoming infected, } \\
\text { caused by climate change }\end{array}$ & $\begin{array}{c}\text { Current situation } \\
\text { Heat increase (50 days) } \\
\text { High heat increase (75 days) }\end{array}$ & $\begin{array}{l}\text { Categorical variable } \\
\text { (moderate; severe) }\end{array}$ \\
\hline Heat Waves & $\begin{array}{l}\text { \# of days per year of extreme heat, } \\
\text { caused by climate change }\end{array}$ & $\begin{array}{c}\text { Current situation ( } 25 \text { days) } \\
\text { Moderate risk } \\
\text { Severe risk }\end{array}$ & $\begin{array}{l}\text { Continuous variable } \\
\text { (days of heat) }\end{array}$ \\
\hline Water shortages & $\begin{array}{l}\text { Hours of water restrictions suffered by } \\
\text { tourist (between } 8 \mathrm{am}-12 \mathrm{pm} \text { ) }\end{array}$ & $\begin{array}{l}\text { Current situation (no restriction) } \\
\text { Moderate restriction }(3 \mathrm{~h}) \\
\text { Severe restriction }(9 \mathrm{~h})\end{array}$ & $\begin{array}{l}\text { Continuous variable } \\
\text { (hours of water } \\
\text { restriction) }\end{array}$ \\
\hline Forest Fires & $\begin{array}{l}\text { Increase in burnt areas, caused by } \\
\text { climate change }\end{array}$ & $\begin{array}{l}\text { Three categories: Current situation; } \\
\text { Moderate increase; High increase }\end{array}$ & $\begin{array}{l}\text { Categorical variable } \\
\text { (moderate; high) }\end{array}$ \\
\hline Marine Habitats & $\begin{array}{l}\text { Deterioration of conservation status } \\
\text { caused by climate change }\end{array}$ & $\begin{array}{c}\text { Three categories: } \\
\text { Current situation; Moderate impact; } \\
\text { Strong impact }\end{array}$ & $\begin{array}{l}\text { Categorical variable } \\
\text { (moderate; strong) }\end{array}$ \\
\hline Land Habitats & $\begin{array}{l}\text { Deterioration of conservation status } \\
\text { caused by climate change }\end{array}$ & $\begin{array}{c}\text { Three categories: } \\
\text { Current situation; Moderate impact; } \\
\text { Strong impact }\end{array}$ & $\begin{array}{l}\text { Categorical variable } \\
\text { (moderate; strong) }\end{array}$ \\
\hline
\end{tabular}

Source: Surveys conducted at countries of origin.

\subsection{Survey Design and Fieldwork}

The questionnaire was structured into three groups of questions. The first group consisted of socio-economic questions related to gender, nationality, age, and the education level of the respondent. 
The second group focused on their travel experience, the number of trips per year and the last island destinations visited. In this section, tourists were asked about the likelihood of staying at home instead of visiting any island destination thought to be at risk of infectious disease caused by climate change. Tourists used a 7-point Likert scale for their answer, ranging from: I will not stay at all (1), to I will stay for sure (7). In this question, we also included other potential climate impacts that could affect tourists' choices.

The final section of the survey was dedicated to the choice questions, aiming at eliciting economic values and tourists' preferences regarding climate change impacts at island destinations. In this section, tourists were given a brief explanation about the risk/impact and the way in which they had to make the choice. Each choice card referred to a different hypothetical scenario. In each scenario, two different EU islands suffered a maximum of five climate change impacts, with infectious disease being one of these possible impacts. Thus, a total of five climate change impacts were presented at the same time in a choice set, given the complexity of choosing an alternative containing many attributes. Three of these impacts were fixed across all choice sets (the other two changed across survey models): infectious diseases, thermal comfort, and beach availability.)

Finally, tourists were asked to choose one option out of the three possible alternatives: visiting either of the two islands at a specified price, or "staying at home" (at zero cost). Figure 2 presents an example of one of the choice cards and the wording of the question. Each respondent answered eight different choice cards (included in the same survey). In total, nine different survey models were utilised (the nine different models are the consequence of having 24 choice cards for each group of five impacts, split into each individual replying to eight cards, and three impacts fixed and the other two being different across model).

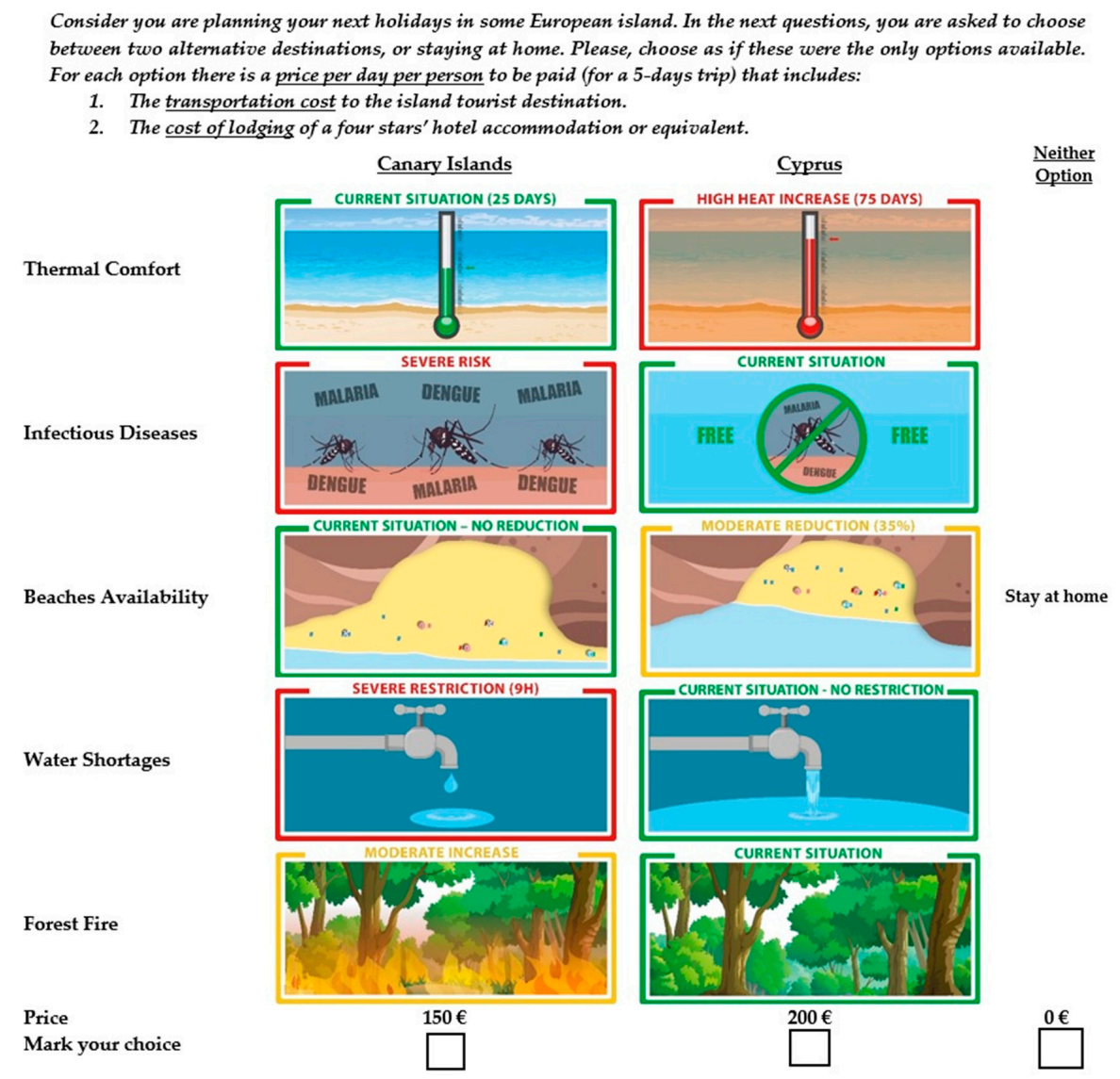

Figure 2. Example of choice card utilised in the survey. 
Focal group meetings were a crucial step before the surveying phase, as they served for the pre-testing of the questionnaire and the evaluation of its effectiveness according to the research needs. Focal groups were conducted on six different islands. Once the questionnaire was pre-tested and the pertinent corrections made to the items that raised comprehension difficulties, the interviews were conducted. A specialised enterprise on online surveying was hired.

A total of $2538 \mathrm{EU}$ citizens (frequent travellers) were surveyed at their country of origin. Four countries were selected: the United Kingdom, Germany, France and Sweden. These countries constitute the main outbound markets for tourism to the European islands, these nationalities altogether accounting for more than $60 \%$ of tourist arrivals in many of the islands or archipelagos under study.

During the fieldwork, a filtering process was done according to the following questions:

(i) The respondents were asked if they had visited any Mediterranean islands or North Atlantic islands (Canary Islands, Madeira, Azores or Antilles) in the previous five years;

(ii) They were asked if they expected to visit any Mediterranean islands or North Atlantic islands (Canary Islands, Madeira, Azores or Antilles) the following year.

If respondents answered "No" to both questions, then the survey was terminated for the individual. Moreover, individuals with missing data and protest responses were excluded from the data analysis. Each subject randomly received a version of the questionnaire, which varied in the specifics of the discrete choice model.

\subsection{Data Analysis}

Frequency analysis was utilised to characterise the general profile of the respondents and their travelling decisions. Table 2 shows the socio-economic profile of the respondents. For some variables, only the categories that were most frequent are shown. The sample is composed in a higher percentage by female subjects and by individuals with university studies, the former representing $52.2 \%$ of the sample. The three age categories considered are evenly distributed in the sample. Regarding the employment status of the respondents, $57.9 \%$ of the surveyed citizens are employed with a salary and $21 \%$ are retired. $23.4 \%$ of the surveyed individuals earn around 2001-2800 EUR/month.

Table 2. Socio-demographic profile.

\begin{tabular}{ccc}
\hline Variable & Category & Freq. \\
\hline Gender & Male & 47.8 \\
& Female & 52.2 \\
Age & $<35$ years & 33.1 \\
& $35-55$ years & 32.4 \\
Education level & $>55$ years & 34.5 \\
& High school or less & 29.0 \\
& Technical/vocational training & 28.7 \\
Employment status & Bachelor's degree or higher & 42.4 \\
& Self-employed & 6.9 \\
& Employed for wage & 57.9 \\
Country of origin & Retired & 21.0 \\
& France & 25.1 \\
& Germany & 24.9 \\
& Sweden & 25.1 \\
Monthly income & United Kingdom & 24.9 \\
& EUR 1201-2000 & 22.2 \\
& EUR 2001-2800 & 23.4 \\
& EUR 2801-3500 & 19.8 \\
& >EUR 3501 & 19.0 \\
\hline
\end{tabular}

Source: Surveys conducted at countries of origin in the SOCLIMPACT project. 
Table 3 shows the descriptive statistics related to tourists' past visits to island destinations. The sample is composed of frequent travellers, as the average number of trips per year is 2.9. Around $77.5 \%$ of the participants have visited Mediterranean islands or North Atlantic islands in recent years. With regards to the specific islands included in this study, the most visited ones were The Canary Islands (34.6\%), The Balearic Islands $(30.4 \%)$ and Crete $(26.3 \%)$. It was important to understand the preferences of the tourists for visiting island destinations in order to ensure that the sample characteristics were aligned with the outbound profile of their countries of origin.

Table 3. Previous visits and disposition towards EU island destinations.

\begin{tabular}{cc}
\hline Variables & \\
\hline \# Overnight trips/year (mean) & 2.9 \\
Visited Mediterranean/North Atlantic islands in the last 5 years (\% Yes) & 77.5 \\
Expect to visit Mediterranean/North Atlantic islands in the next year (\% Yes) & 85.6 \\
Islands previously visited (\%): & 34.6 \\
Canary Islands & 30.4 \\
Balearic Islands & 26.3 \\
Crete & 22.8 \\
Cyprus & 19.7 \\
Malta & 15.7 \\
Madeira & 15.3 \\
Corsica & 13.4 \\
Sicily & 12.0 \\
Sardinia & 10.5 \\
West Indies & 7.1 \\
Azores & 4.3 \\
Fehmarn & \\
\hline
\end{tabular}

The majority of tourists, $85.6 \%$ of the sample, were willing to visit these islands in the following year. It should be highlighted that surveys were carried out in January 2020, before the COVID-19 outbreak in Europe. In the current situation all travelers' dispositions are conditioned to eachcountry's restrictions.

Finally, the alternative-specific conditional logit (McFadden's choice) model was run using the software STATA14. This Asc-logit model requires multiple observations for each case. Moreover, the alternative-specific constants have been considered because the alternatives are labelled, and it might influence differences in utilities between the alternatives. In this model, the explanatory variables used are the corresponding climate change impacts that may take place at the destination, the hypothetical price per day to visit the island (on a five-day trip and staying in a four-star hotel), the individuals' socio-demographic characteristics, and islands fixed effects.

\section{Results}

This section is structured into two subsections. The first one presents descriptive statistics pointing at the fact that tourists may choose to stay at home if island destinations are affected by the risk of infectious disease events and other CC impacts that could potentially occur there. The second part presents the results of the choice model.

\subsection{Willingness to Visit Islands Affected by Infectious Diseases and Other Climate-Induced Impacts}

Tourists were asked if they would keep their plans to visit an island in the near future if a possible risk of infectious disease was to occur there. At the same time, the question included other risks that could potentially affect the destination choice of tourists. Figure 3 presents the percentage of respondents that chose to stay at home due to the various risks associated with CC. The highest percentages are found where infectious diseases became widespread at the island destinations, whereby more than $50 \%$ of the sample chose not to visit the islands. This denotes a high risk-aversion to infectious disease events per se and also in relation to most of the possible impacts induced by CC. 


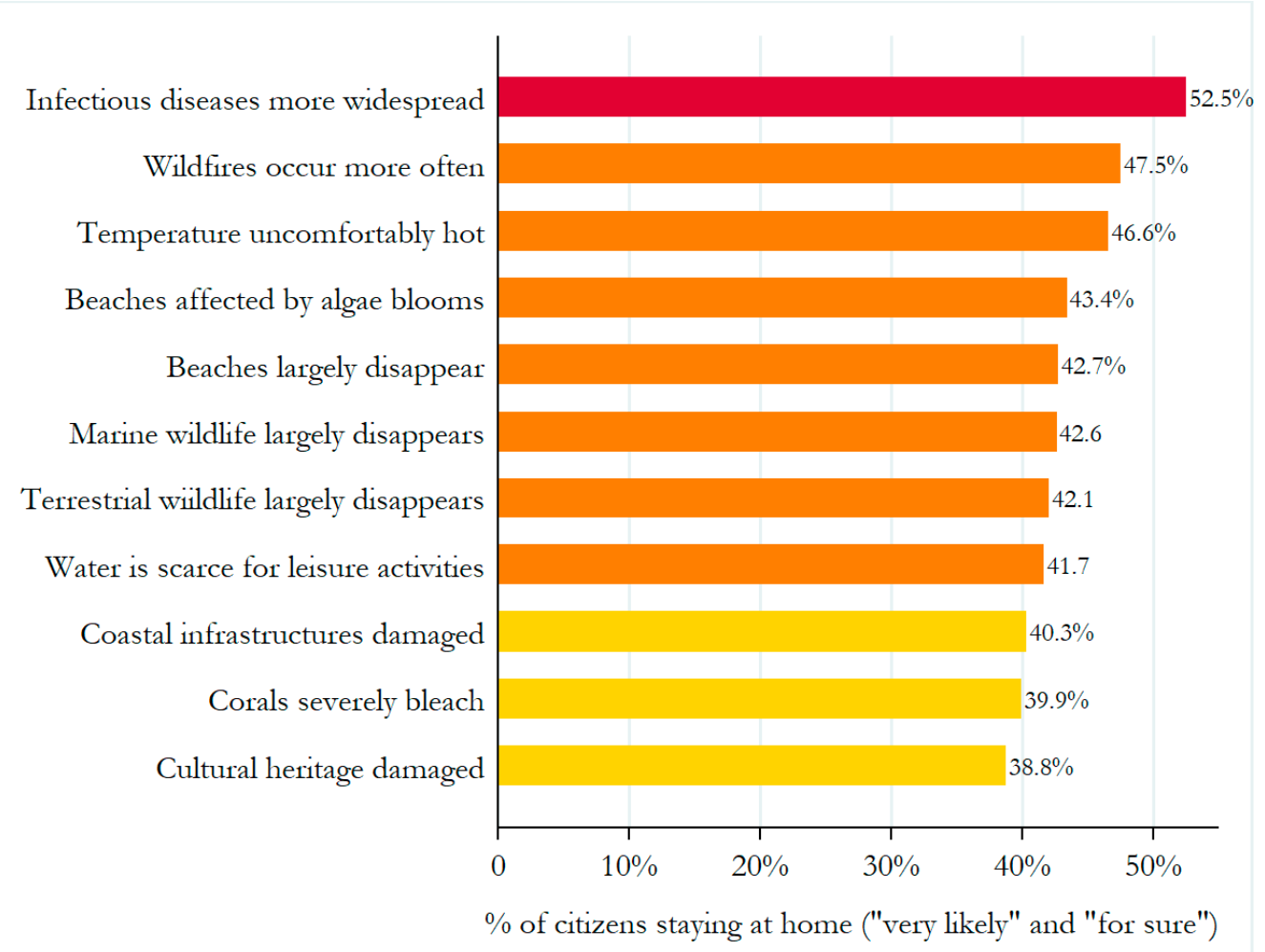

Figure 3. Tourists' decisions to stay at home if islands are affected by climate change impacts.

\subsection{Choice Model Results}

The Asc-logistic regression provided the parameter values and standard errors for each attribute, as well as the reductions in willingness to pay (negative) to visit the islands under each specific impact of climate change. The coefficients allow for the computation of changes in the willingness to pay to visit one island if an attribute changes, while the others remain constant (ceteris paribus). The socio-demographic variables were also included in the regression, although the results are very similar if these variables are not considered. This means that WTP values are adjusted to individuals' characteristics and income.

Table 4 presents the results of the regression. Results reveal that tourists would visit island destinations thought to be at a high risk of vector born outbreaks if the price per tour package decreases by EUR 398. The WTP should be interpreted for a 5-days trip, given that the CC impact will be present for the whole trip. This figure goes down to EUR 157 if the risk is moderate instead of severe. According to official statistics, these numbers represent a decrease of about $50-100 \%$ in tourists' daily average expenditure at the studied island destinations, depending on the island considered, and if the risk of becoming infected is severe. However, if the risk is moderate, the decrease in daily expenditure would range between $20 \%$ and $50 \%$.

It is important to point out that, although infectious diseases are the variable with the highest negative values of WTP, considering severe and moderate risks together, other attributes such as forest fire events also provide a WTP decrease of about EUR 200 under severe risk level. On the contrary, the WTP for visiting islands in a CC scenario of beach losses or heat waves decreases only by EUR 1.85 and EUR 5.05, respectively. These results suggest that the occurrence of infectious diseases have the greatest impact on the deterioration of image and the value tourists give to the island destinations. In relative terms, the islands' value is more negatively influenced by those CC risks that are related to extreme disruptive events affecting health and security, from the perception of the tourists that visit them. 
Table 4. Estimation results for tourists' willingness-to-pay (WTP) for visiting island destinations under climate change (CC) risks.

\begin{tabular}{|c|c|c|}
\hline & Estimation & WTP (EUR) \\
\hline Infectious diseases (Severe) & $-0.73540 * *(0.034)$ & -397.51 \\
\hline Infectious diseases (Moderate) & $-0.29020 * *(0.032)$ & -156.86 \\
\hline Heat Waves & $-0.00934 * *(0.001)$ & -5.05 \\
\hline Beach loss & $-0.00343^{* *}(0.00)$ & -1.85 \\
\hline Water shortages & $-0.02919 * *(0.005)$ & -15.78 \\
\hline Forest fires (Moderate) & $-0.15636^{* *}(0.05)$ & -84.52 \\
\hline Forest fires (High) & $-0.46624 * *(0.054)$ & -252.02 \\
\hline Marine habitats (Moderate) & $-0.09523 *(0.042)$ & -51.48 \\
\hline Marine habitats (Strong) & $-0.28467 * *(0.045)$ & -153.88 \\
\hline Terrestrial habitats (Moderate) & $-0.22630 * *(0.044)$ & -122.32 \\
\hline Terrestrial habitats (Strong) & $-0.38184 * *(0.049)$ & -206.40 \\
\hline Infrastructures (Moderate) & $-0.21595 * *(0.045)$ & -116.73 \\
\hline Infrastructures (Strong) & $-0.26488 * *(0.044)$ & 143.18 \\
\hline Cultural heritage (Moderate) & $-0.12128 * *(0.046)$ & -65.56 \\
\hline Cultural heritage (Strong) & $-0.26799 * *(0.046)$ & -144.86 \\
\hline Price & $-0.00185^{* *}(0.000)$ & - \\
\hline Antilles & $2.8168 *(0.316)$ & 1522.60 \\
\hline Azores & $2.73110 *(0.291)$ & 1476.27 \\
\hline Balearic Islands & $2.78419 *(0.291)$ & 1504.97 \\
\hline Canary Islands & $2.98224 *(0.287)$ & 1612.02 \\
\hline Corsica & $2.86439 *(0.29)$ & 1548.32 \\
\hline Crete & $3.00329 *(0.29)$ & 1623.40 \\
\hline Cyprus & $2.92211 *(0.291)$ & 1579.52 \\
\hline Madeira & $2.85363 *(0.289)$ & 1542.50 \\
\hline Malta & $2.88672 *(0.286)$ & 1560.39 \\
\hline Sardinia & $2.89303 *(0.288)$ & 1563.80 \\
\hline Sicily & $2.86384 *(0.29)$ & 1548.02 \\
\hline No. of individuals & \multicolumn{2}{|c|}{2538} \\
\hline
\end{tabular}

Note: ${ }^{* *} p<0.01,{ }^{*} p<0.05$, significance test levels. Standard errors within parentheses. Socio-demographic characteristics included in the regression.

\section{Discussion}

Climate data is commonly employed as a differentiating resource of the destination to improve its image and achieve a better profile because of its attractive effect on tourist demand [28]. Climate is also a variable taken into account in the design and combination of tourism products and packages in order to take advantage of climatic characteristics of the destinations [29]. This strategy allows destinations to achieve greater market success and enjoy greater economic impacts from tourism.

This research shows that tourists' perceived value of islands is negatively affected when climate change is likely to occur, which is reflected in a decreased WTP to visit these destinations. Besides, if CC leads to a greater health risk caused by infectious disease events, even moderate and severe levels, the WTP of tourists is more negatively influenced than for the rest of the risks. Consequently, island destinations must not only be aware of their natural features and climatic conditions when designing the supply, but they also need to deal with effective mechanisms of prevention, preparedness and responsiveness to specific climate risks that cause health insecurity in tourists. At this scale, planning and promotion should not only exploit the advantages of climate conditions, but also attempt to better inform tourists about the progress made in prevention to CC risks.

As climate is outside the control of destination managers, it is necessary to work in two directions: (i) identify and prioritise optimal adaptation packages to face those CC impacts that most affect islands' value and image; (ii) exploit the advantages of new climate services, health insurance, and the implementation of early warning systems as a means to generate added-value for the tourist. In other words, if tourists feel that they can make more informed decisions about when they can visit 
islands with the lowest possible health risks, destination competitiveness and image will be improved. Both destination managers and tourism promoters should not only work towards the implementation of the best possible practices and emergency plans in response to health risks and extreme events, but also exploit this progress by including it in the tourism promotion and communication of the destination.

Close collaboration between tourism authorities, the tourism industry and other public and private actors is required, posing a challenge for tourism governance. However, it should be possible to promote technological progress in the fight against climate change, while promoting competitive advantages for island destinations. This is of crucial importance at the time of this health crisis (COVID-19) we are currently living through. It is the moment for tourist destinations to decide how they want to re-adapt their tourism systems and accelerate the transformation of sustainable and resilient tourism. Some destinations will undoubtedly reconsider the nature of their tourism industry without substantial institutional and governmental interventions [14], while for others this would be a limiting factor.

\section{Conclusions}

Climate change generates important economic effects on the tourism industry, since both the supply and demand of tourism services depend upon the quality and the management of a set of environmental attributes which are under threat of modification by CC. This paper provides a working specification of the relationship between potential infectious disease events caused by climate change and tourists' decisions to stay at home and willingness to pay to visit island destinations. Given the multiple ways in which climate change can impact tourist destinations, the analysis also integrates other impacts, thus leading to a more holistic picture of tourists' preferences and behavioural responses to climate change.

The main contributions of this article are that (i) it provides a better and wider understanding of tourists' aversion to infectious disease events caused by CC when they are considering visiting island destinations, and (ii) it shows that the risk of infectious diseases is a dominant factor for explaining changes in tourism expenditure in the context of island destinations facing several climate-related risks. That is, this research has shown that the potential risk of vector born outbreaks impacts more negatively on tourists' willingness to pay to visit islands than other climate-related impacts, such as beach loss or forest fires.

From a policy perspective, this study allows the potential economic losses that a changing climate can generate for island destinations to be measured, which highlights the importance of incorporating a financial dimension within the adaptation and risk management strategies of these regions.

If we take into consideration the fact that this study was conducted in January 2020, before the current health emergency caused by COVID-19, its significance is even greater, since it highlights how seriously disruptive a future similar climatic event could be. Thus, the importance of prevention, preparedness and response strategies is justified by the high value tourists give to health security at tourist destinations.

This study faces various limitations that substantially reduce the potential generalisation of its results and the scope of its conclusions. First, the present work only focuses on island tourism (the application is based on tourists' decisions to visit islands). Therefore there is need to consider evidence from alternative destinations. Second, tourists from only four European countries were interviewed, these being surveyed at their country of origin. Although these countries are the most important tourism markets for the islands, it is necessary to contrast evidence with surveys conducted at destinations, as tourists' preferences and WTP could be different if they are visiting the island at the moment of being interviewed. Moreover, the tourism market composition varies between the islands. Third, surveys were conducted right at the beginning of the COVID-19 period (some news reports were beginning to appear in the European media). In the current scenario, these values could be much higher and also be influenced by destinations' strategies and their management of the current health crisis. Finally, the investigation of the climatic aspects, and how they influence tourist decisions, 
does require a more profound and detailed examination of the real impacts at each of the islands analysed, based on physical and meteorological measurements. Although this research has focused on tourists in general, the extrapolation of results for more specific tourist segments (i.e., vulnerable groups) and experiences is a matter of further research.

Future research can analyse the moderating effect of the destination image and the importance tourists give to each of the attributes of the destination at risk of being affected by CC. This relationship is important, as changes in the destination image are good predictors of destination choice, and, in some cases, of tourists' satisfaction and expenditure decisions. This will also serve to better clarify whether WTP depends on the importance tourists give to these attributes. Additionally, a post-COVID analysis is required in order to measure how preferences or WTP are likely to change and to analyse the gap between hypothetical and real scenarios of tourist decision making. Finally, the analysis of adaptation measures and risk management at destinations should also be analysed as they have the potential to impact the value and image of destinations from the perception of the tourist.

Author Contributions: Conceptualization, C.J.L. and M.M.G.H.; methodology, Y.E.L.-G. and C.G.G.; data curation, C.G.G.; writing - original draft preparation, Y.E.L.-G.; writing-review and editing, M.M.G.H. and C.G.G.; visualization, Y.E.L.-G.; supervision, C.J.L.; funding acquisition, all. All authors have read and agreed to the published version of the manuscript.

Funding: Research for this paper has been supported by European Union's Horizon 2020 research and innovation programme under grant agreement No. 776661, project "SOCLIMPACT-DownScaling CLImate imPACTs and decarbonisation pathways in EU islands and enhancing socio-economic and non-market evaluation of Climate Change for Europe, for 2050 and beyond".

Conflicts of Interest: The authors declare no conflict of interest.

\section{References}

1. Ciscar, J.C.; Iglesias, A.; Feyen, L.; Szabó, L.; Van Regemorter, D.; Amelung, B.; Garrote, L. Physical and economic consequences of climate change in Europe. Proc. Natl. Acad. Sci. USA 2011, 108, 2678-2683. [CrossRef] [PubMed]

2. Hall, C.M.; Gössling, S.; Scott, D. Tourism and Climate Change: Impacts, Adaptation and Mitigation; Routledge: Abingdon, UK, 2012.

3. Cheer, J.M.; Lew, A.A. (Eds.) Tourism, Resilience and Sustainability: Adapting to Social, Political and Economic Change; Routledge: Abingdon, UK, 2017.

4. Lau, C.; Smythe, L.; Craig, S.B.; Weinstein, P. Climate change, flooding, urbanisation and leptospirosis: Fuelling the fire? Trans. R. Soc. Trop. Med. Hyg. 2010, 104, 631-638. [CrossRef]

5. Liu, B.; Pennington-Gray, L. Managing Health-related Crises in the Cruise Industry. In Cruise Ship Tourism; CABI: Egham, UK, 2017; pp. 220-235.

6. Lam-González, Y.E.; León, C.J.; de Leon, J. Assessing the effects of the climatic satisfaction on nautical tourists' on-site activities and expenditure decisions. J. Destin. Mark. Manag. 2019, 14, 100372. [CrossRef]

7. Kaján, E.; Saarinen, J. Tourism, climate change and adaptation: A review. Curr. Issues Tour. 2013, 16, 167-195. [CrossRef]

8. Franzoni, S. Measuring the sustainability performance of the tourism sector. Tour. Manag. Perspect. 2015, 16, 22-27. [CrossRef]

9. Becken, S. The importance of climate and weather for tourism. Literature review. In LEaP Land Environment E People; Miscellaneous Publications; Lincoln University: Lincoln, UK, 2010.

10. Fang, Y.; Yin, J.; Wu, B. Climate change and tourism: A scientometric analysis using CiteSpace. J. Sustain. Tour. 2018, 26, 108-126. [CrossRef]

11. Steiger, R.; Scott, D.; Abegg, B.; Pons, M.; Aall, C. A critical review of climate change risk for ski tourism. Curr. Issues Tour. 2019, 22, 1343-1379. [CrossRef]

12. Lau, C.; Smythe, L.; Weinstein, P. Leptospirosis: An emerging disease in travellers. Travel Med. Infect. Dis. 2010, 8, 33-39. [CrossRef]

13. Mavalankar, D.; Puwar, T.I.; Murtola, T.M.; Vasan, S.S. Quantifying the Impact of Chikungunya and Dengue on Tourism Revenues; WP Series of the Indian Institute of Management Ahmedabad; The Indian Institute of Management Ahmedabad: Ahmedabad, India, 2009. 
14. Ryu, S.; Gao, H.; Wong, J.Y.; Shiu, E.Y.C.; Xiao, J.; Fong, M.W.; Cowling, B.J. Nonpharmaceutical measures for pandemic influenza in nonhealthcare settings-International travel-Related measures. Emerg. Infect. Dis. 2020, 26, 961-966. [CrossRef]

15. Hall, C.M.; Scott, D.; Gössling, S. Pandemics, transformations and tourism: Be careful what you wish for. Tour. Geogr. 2020, 22, 577-598. [CrossRef]

16. Goodwin, H.; Francis, J. Ethical and responsible tourism: Consumer trends in the UK. J. Vacat. Mark. 2003, 9, 271-284. [CrossRef]

17. Lee, W.H.; Moscardo, G. Understanding the impact of ecotourism resort experiences on tourists' environmental attitudes and behavioural intentions. J. Sustain. Tour. 2005, 13, 546-565. [CrossRef]

18. Hoyos, D. The state of the art of environmental valuation with discrete choice experiments. Ecol. Econ. 2010, 69, 1595-1603. [CrossRef]

19. León, C.J.; de León, J.; Araña, J.E.; González, M.M. Tourists' preferences for congestion, residents' welfare and the ecosystems in a national park. Ecol. Econ. 2015, 118, 21-29. [CrossRef]

20. Araña, J.E.; León, C.J. Scale-perception bias in the valuation of environmental risks. Appl. Econ. 2012, 44, 2607-2617. [CrossRef]

21. Araña, J.E.; León, C.J. Correcting for scale perception bias in tourist satisfaction surveys. J. Travel Res. 2013, 52, 772-788. [CrossRef]

22. Araña, J.E.; León, C.J. Dynamic hypothetical bias in discrete choice experiments: Evidence from measuring the impact of corporate social responsibility on consumers demand. Ecol. Econ. 2013, 87, 53-61. [CrossRef]

23. Lancaster, K. A new approach to consumer theory. J. Political Econ. 1996, 74, 132-157. [CrossRef]

24. Organisation for Economic Co-operation and Development. Cost-Benefit Analysis and the Environment: Further Developments and Policy Use; OECD Publishing: Paris, France, 2018.

25. McFadden, D. Conditional logit analysis of qualitative choice behavior. In Frontiers in Econometrics; Academic Press: New York, NY, USA, 1973.

26. Greene, W. Functional forms for the negative binomial model for count data. Econ. Lett. 2008, 99, 585-590. [CrossRef]

27. Hanemann, W.M. Discrete/continuous models of consumer demand. Econom. J. Econom. Soc. 1984, 541-561. [CrossRef]

28. Matzarakis, A.; Endler, C.; Nastos, P.T. Quantification of climate-tourism potential for Athens, Greece-recent and future climate simulations. Glob. Nest J. 2014, 16, 43-51.

29. Moreno, A.; Amelung, B.; Santamarta, L. Linking beach recreation to weather conditions: A case study in Zandvoort, Netherlands. Tour. Mar. Environ. 2008, 5, 111-119. [CrossRef]

Publisher's Note: MDPI stays neutral with regard to jurisdictional claims in published maps and institutional affiliations.

(C) 2020 by the authors. Licensee MDPI, Basel, Switzerland. This article is an open access article distributed under the terms and conditions of the Creative Commons Attribution (CC BY) license (http://creativecommons.org/licenses/by/4.0/). 